\title{
TRANSFORMATION OF ZNO-BASED STRUCTURES UNDER HEAVY MO DOPING: DEFECT STATES AND LUMINESCENCE
}

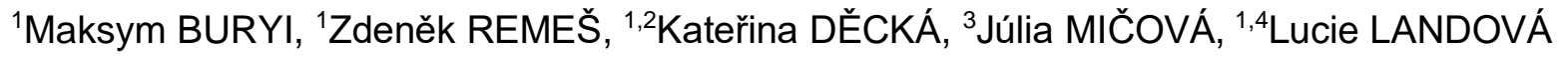 \\ ${ }^{1}$ Institute of Physics CAS in Prague, Prague, Czech Republic, EU, buryi@fzu.cz \\ ${ }^{2}$ Czech Technical University in Prague, Faculty of Nuclear Sciences and Physical Engineering, Prague, \\ Czech Republic, EU, katerina.decka@fifi.cvut.cz \\ ${ }^{3}$ Institute of Chemistry SAS, Bratislava, Slovakia, chemjumi@savba.sk \\ ${ }^{4}$ Czech Technical University in Prague, Faculty of Electrical Engineering, Prague, Czech Republic, EU, \\ abelova@fzu.cz
}

https://doi.org/10.37904/nanocon.2021.4321

\begin{abstract}
Hydrothermally grown $\mathrm{ZnO}$-based structures were heavily doped with $\mathrm{Mo}$ (various doping levels from 2 to $25 \%$ ). Mo was found to strongly affect the structure and morphology of $\mathrm{ZnO}$, resulting in a complex mixture of zinc oxide and molybdenum. Moreover, the transformation of material phases upon the increased Mo content was observed. $\mathrm{ZnO}$ phase was observed only at low Mo doping level ( 2 and $5 \%$ ). This correlated very well to the changes in the luminescence and electron paramagnetic resonance signals.
\end{abstract}

Keywords: $\mathrm{ZnO}$, Mo doping, material phase transformation, luminescence, electron paramagnetic resonance

\section{INTRODUCTION}

$\mathrm{ZnO}$ is a smart material which finds application in various fields of human activities: as scintillator, including application in time-of-flight positron emission tomography [1,2]; as electrode material in supercapacitors; in photocatalysis, energy harvesting and storage systems [3,4].

In majority of cases luminescence of $\mathrm{ZnO}$ nanostructures is composed of fast exciton luminescence peaks having maximum in near ultraviolet region at about $380 \mathrm{~nm}$ with decay time in the order of hundreds of ps and a relatively slow defects-related bands decay time in the order of tens of $\mu \mathrm{s}$. For example, the experimentally observed broad red bands ranging from 1 to $2 \mathrm{eV}$ were related to zinc $\left(V_{z n}\right)$ or oxygen $\left(V_{0}\right)$ vacancies [5]. The red emission bands $(1.8-2 \mathrm{eV})$ related to $V_{Z_{n}}[5,6]$ were recently also observed in the hydrothermally grown $\mathrm{ZnO}$ nano- and microrods [7,8]. It is known that low-level Mo doping (below $1 \%$ ) can positively affect the luminescence properties of $\mathrm{ZnO}$ (both defect-related and exciton luminescence) [7,8], whereas doping with 10 and $30 \%$ of Mo deteriorates them. Moreover, Mo has the tendency to couple with $\mathrm{ZnO}$ creating some new phase other than $\mathrm{ZnO}$ itself.

$\mathrm{ZnO}$ structure can also be characterized by the typical electron paramagnetic resonance (EPR) single-line signal observed at the $g$ factor $g \approx 1.96$ ascribed to the shallow $\mathrm{Ga}, \mathrm{Al}, \mathrm{H}$ donors (SD) [9-12], the $\mathrm{Zn}^{+}+\mathrm{D}$ complex, $\mathrm{D}=\mathrm{Ga}, \mathrm{Al}, \mathrm{H}$ [8]. The influence of Mo on this shallow donor was studied earlier [6,8] in the $\mathrm{ZnO}: \mathrm{Mo}(0.05,0.25,1 \%)$ and $\mathrm{ZnO}: \mathrm{Mo}(10,30 \%)$.

However, there is no systematic investigation of the influence of Mo at the doping level within $2-25 \%$ on $\mathrm{ZnO}$ structure, morphology and creation of zinc-molybdenum complex oxides, luminescence and magnetic properties. Therefore, this is the aim of the present paper. 


\section{EXPERIMENTAL}

\subsection{Samples preparation}

All reagents were analytical grade and were used as-received without further purification. Zinc nitrate hexahydrate $\left(\mathrm{Zn}\left(\mathrm{NO}_{3}\right)_{2} \cdot 6 \mathrm{H}_{2} \mathrm{O}\right)$ and hexamethylenetetramine $\left(\mathrm{HMTA}, \mathrm{C}_{6} \mathrm{H}_{12} \mathrm{~N}_{4}\right)$ were purchased from Slavus and ammonium heptamolybdate tetrahydrate $\left(\mathrm{NH}_{4}\right)_{6} \mathrm{Mo}_{7} \mathrm{O}_{24} \cdot 4 \mathrm{H}_{2} \mathrm{O}(\mathrm{NHMO})$ was obtained from Sigma-Aldrich. Deionized water was purified with a system So Safe Water Technologies, having a conductivity $0.20 \mu \mathrm{S} \cdot \mathrm{cm}^{-1}$ at $25^{\circ} \mathrm{C}$.

Undoped and Mo-doped $\mathrm{ZnO}$ nanorods with the Mo content 2-25\% were prepared by the hydrothermal growth method. First, the corresponding stoichiometric amounts of $\mathrm{Zn}\left(\mathrm{NO}_{3}\right)_{2} \cdot 6 \mathrm{H}_{2} \mathrm{O}$ and $\left(\mathrm{NH}_{4}\right)_{6} \mathrm{Mo}_{7} \mathrm{O}_{24} \cdot 4 \mathrm{H}_{2} \mathrm{O}$, were dissolved in $200 \mathrm{ml}$ and $50 \mathrm{ml}$ of deionized water, respectively, with vigorous stirring by a magnetic stirrer. At the same time, a $25 \mathrm{mM}$ aqueous solution of HMTA was prepared. All the solutions were filtered through a Whatman 2 filter. Subsequently, the filtered solutions were stirred vigorously for $15 \mathrm{~min}$. The nominal concentration of the $\mathrm{ZnO}: \mathrm{Mo}(2-25 \%)$ in the final suspensions was $25 \mathrm{mM}$. The solution of HMTA was added to the mixture. Stirring of the reaction mixture was followed by hydrothermal growth of nanorods by heating at $90{ }^{\circ} \mathrm{C}$ for 3 hours. The grown nanorods were isolated and then purified (removal of residual salts), washing 5 times with deionized water and subsequent centrifugation at 18,000 rpm (RCF: 23,542 $\mathrm{x} \mathrm{g}$ ) for 15 minutes. Finally, the samples were lyophilized.

The amount of powder samples was approximately the same in all experiments.

\subsection{Experimental techniques}

XRD on powder samples was performed using RigakuMiniFlex 600 (Ni-filtered Cu- $\mathrm{K}_{a 1,2}$ radiation) equipped with the Nal:TI scintillation detector and XRD patterns were compared to the relevant records in the ICDD PDF-2 database (version 2013). The angular range was $10^{\circ}-80^{\circ}$, with a step of $0.02^{\circ}$ and a scanning speed of $2^{\circ} / \mathrm{min}$.

The size and morphology of ZnO NRs has been checked by scanning electron microscopy (SEM) using MAIA3, TESCAN electron microscope with the in-beam SE detector placed in objective lens and the electron beam energy $5 \mathrm{keV}$.

The steady-state photoluminescence $(\mathrm{PL})$ spectra in the $350-800 \mathrm{~nm}$ spectral range were excited at frequency $333 \mathrm{~Hz}$ by pulsed $1 \mathrm{~mW}$ UV LED optically filtered by narrow band-pass filter centered at the wavelength $340 \mathrm{~nm}$ and recorded with $2 \mathrm{~nm}$ spectral resolution using the spectrally calibrated $\mathrm{f} / 4$ double gratings monochromator, long-pass filters, a red sensitive photomultiplier, current preamplifier $(10 \mu \mathrm{A} / \mathrm{V})$ and a lock-in amplifier referenced to the UV LED frequency. All PL spectra were spectrally calibrated, normalized at the wavelength $355 \mathrm{~nm}$ on the same value (dominated by optical scattering of excitation light) and converted from wavelength to energy scale taking into account the Jacobian correction [13]. PL spectra were measured with $5 \mathrm{mg} \mathrm{ZnO}$ powder pressed in a Suprasil glass tube with the inner (outer) diameter $2 \mathrm{~mm}(3 \mathrm{~mm})$ featuring a low fluorescence background.

EPR measurements were performed with a commercial Bruker EMXplus spectrometer in the X-band $(9.4 \mathrm{GHz})$ within the 4-296 K temperature range using Oxford Instruments ESR900 cryostat. The spectrometer sensitivity is about $10^{12}$ spins $/ \mathrm{mT}$.

\section{RESULTS AND DISCUSSION}

\subsection{Phase purity and morphology}

The XRD patterns of ZnO:Mo(2-25\%) samples are demonstrated in Figure 1. 


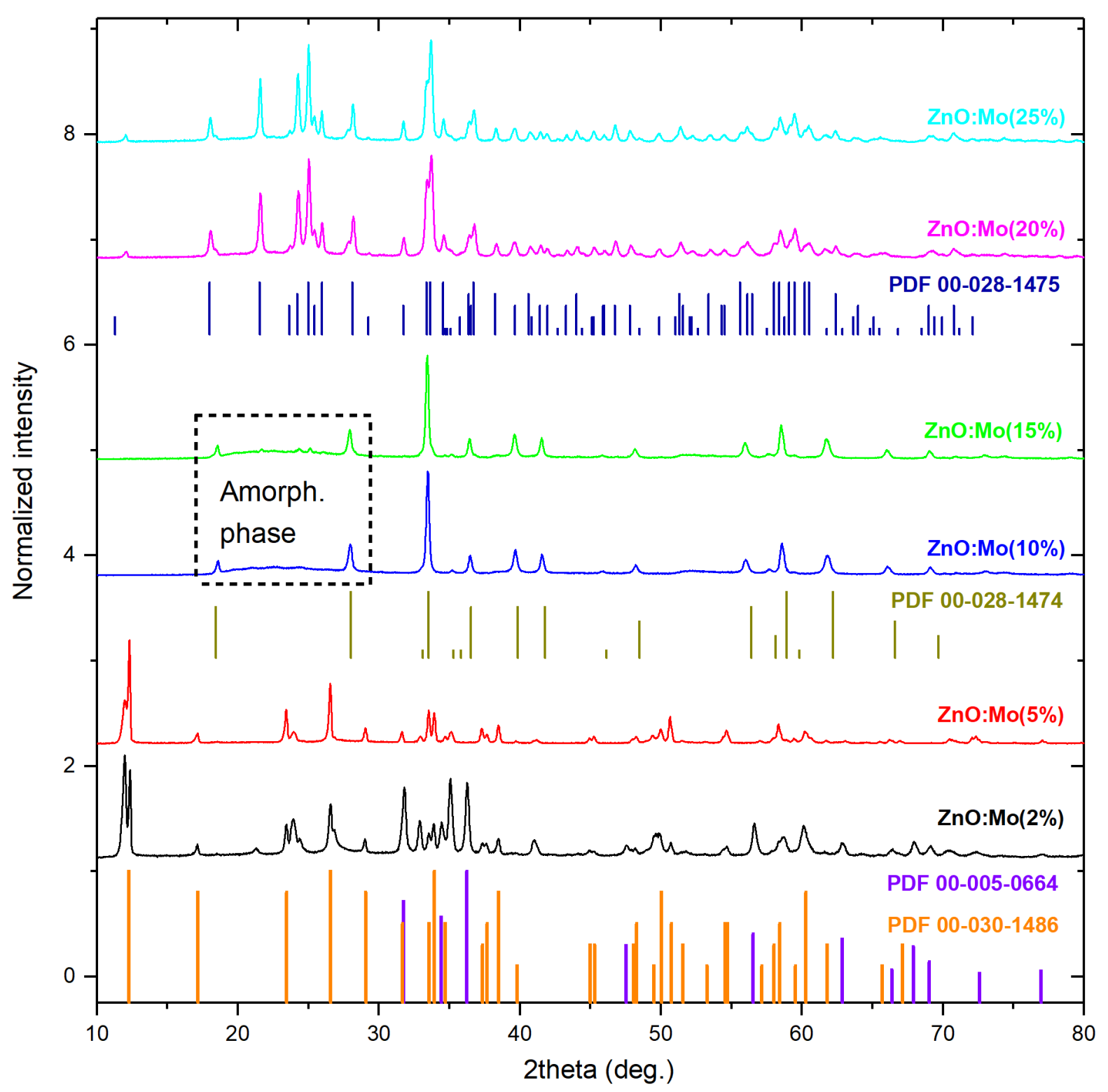

Figure $1 \mathrm{XRD}$ patterns of the $\mathrm{ZnO}: \mathrm{Mo}(2-25 \%)$. The positions of the XRD reflections are indicated by vertical solid lines distinguished by color according to the corresponding record in the ICDD PDF-2 database: PDF 00-005-0664 (hexagonal ZnO), PDF 00-030-1486 $\left(\mathrm{Zn}_{5} \mathrm{Mo}_{2} \mathrm{O}_{11} \cdot 5 \mathrm{H}_{2} \mathrm{O}\right)$, PDF 00-028-1474 ( $\left.\mathrm{MoO}_{3} \cdot 2 \mathrm{ZnO} \cdot \mathrm{H}_{2} \mathrm{O}\right)$,

PDF 00-028-1475 $\left(2 \mathrm{MoO}_{3} \cdot 3 \mathrm{ZnO} \cdot \mathrm{H}_{2} \mathrm{O}\right)$.

The XRD patterns of $\mathrm{ZnO}: \mathrm{Mo}(2-25 \%)$ are very complex, especially at the largest Mo content, composed of different material phases (they were tentatively ascribed to the complex zinc-molybdenum oxides). The negligibly small presence of $\mathrm{ZnO}$ phase could be detected only in the $\mathrm{ZnO}: \mathrm{Mo}(2,5 \%)$ dominated by some other material phase. This phase was tentatively ascribed to $\mathrm{Zn}_{5} \mathrm{Mo}_{2} \mathrm{O}_{11} \cdot 5 \mathrm{H}_{2} \mathrm{O}$. Further increase of the Mo content to 10 and $15 \%$ resulted in the disappearance of the $\mathrm{ZnO}$ phase and transformation of the $\mathrm{Zn}_{5} \mathrm{Mo}_{2} \mathrm{O}_{11} \cdot 5 \mathrm{H}_{2} \mathrm{O}$ to the $\mathrm{MoO}_{3} \cdot 2 \mathrm{ZnO} \cdot \mathrm{H}_{2} \mathrm{O}$. Moreover, some unknown amorphous phase appeared. Its origin is unknown. Further increase of the $\mathrm{Mo}$ content to 20 and $25 \%$ results in the $\mathrm{MoO}_{3} \cdot 2 \mathrm{ZnO} \cdot \mathrm{H}_{2} \mathrm{O}$ transformation into the $2 \mathrm{MoO}_{3} \cdot 3 \mathrm{ZnO} \cdot \mathrm{H}_{2} \mathrm{O}$ while amorphous phase disappeared.

SEM provides an insight into the morphology of the $\mathrm{ZnO}: \mathrm{Mo}(2-25 \%)$ samples. The corresponding images are shown in Figure 2. The $\mathrm{ZnO}: \mathrm{Mo}(2 \%)$ sample is the only consisting of hexagonal prismoid microrods, in average, of the size 1-2 $\mu \mathrm{m}$ in circumference and over $3 \mu \mathrm{m}$ long (Figure 2A). However, the microrods are 
outnumbered by the irregular flat slab-like structures with the averaged area of about 1-10 $\mu \mathrm{m}^{2}$. Interestingly, the $\mathrm{ZnO}: \mathrm{Mo}(5 \%)$ sample is composed of hexagons, varying in "diameter" within the 5-10 $\mu \mathrm{m}$ range and about $0.5 \mu \mathrm{m}$ thick (Figure 2B).

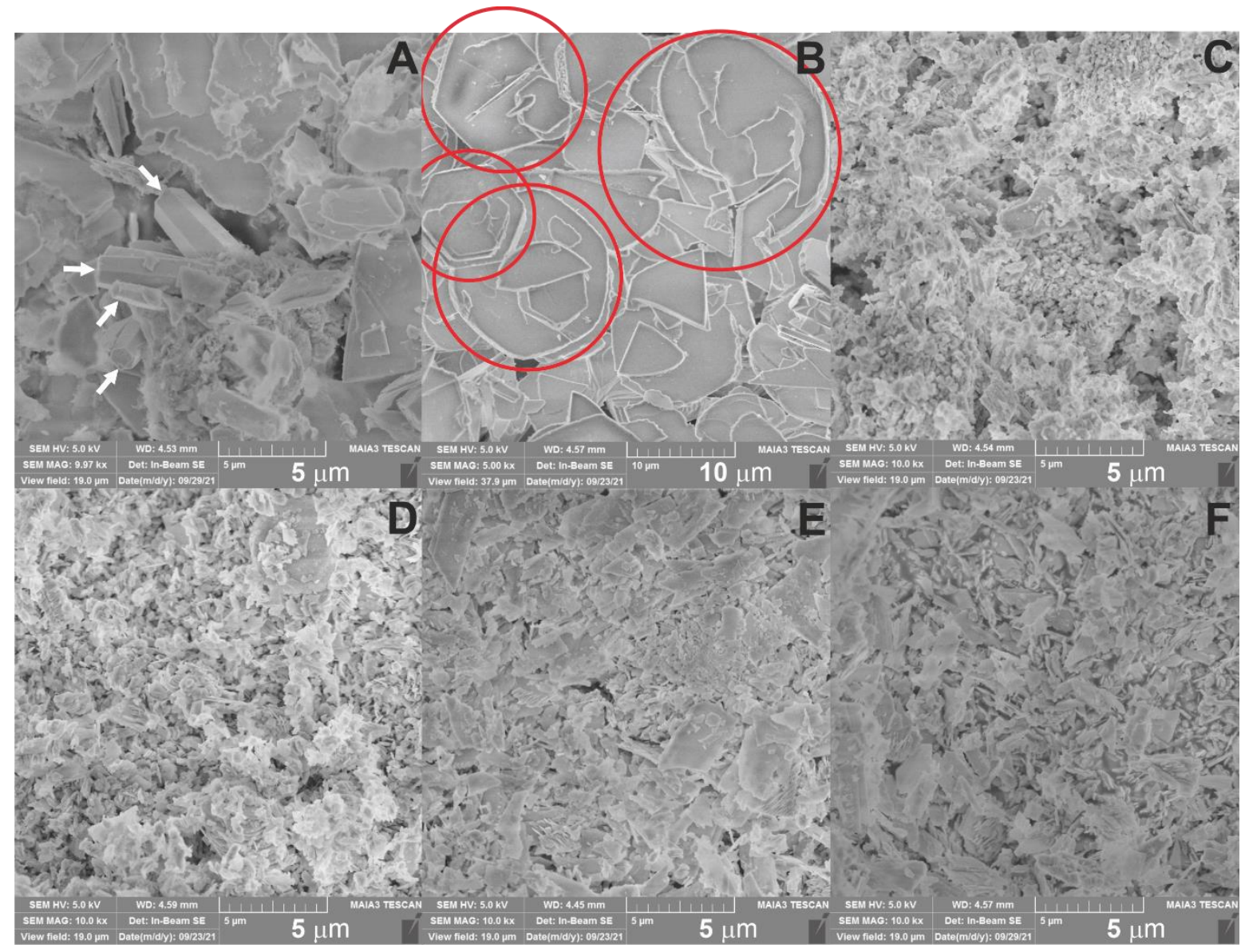

Figure 2 SEM images of the $\mathrm{ZnO}: \mathrm{Mo}(2-25 \%)$ samples with different magnification as indicated in Figures: A - ZnO:Mo(2\%); B - ZnO:Mo(5\%); C - ZnO:Mo(10\%); D - ZnO:Mo(15\%); E - ZnO:Mo(20\%); F $\mathrm{ZnO}: \mathrm{Mo}(25 \%) . \mathrm{ZnO}$ microrods are stressed by white arrows. Hexagons are marked by red circles.

The $\mathrm{ZnO}: \mathrm{Mo}(10-25 \%)$ samples consist of flake-like sheared structures with the averaged area about $0.25 \mu \mathrm{m}^{2}$ (Figures 2C-F). In the $\mathrm{ZnO}: \mathrm{Mo}(20,25 \%)$ samples the flakes are getting mixed with the larger slabs of the averaged area of about $5 \mu \mathrm{m}^{2}$. This is consistent with the previous study of the $\mathrm{ZnO}: \mathrm{Mo}(30 \%)$ [7].

Based on the XRD and SEM analyses one may conclude that the increased Mo doping level results in the phase transformation and changes in morphology of the $\mathrm{ZnO}: \mathrm{Mo}(2-25 \%)$ samples.

\subsection{PL and EPR characterization}

$\mathrm{PL}$ spectra have been measured in all the $\mathrm{ZnO}: \mathrm{Mo}(2-25 \%)$ samples at room temperature as can be seen in Figure 3A. The spectrum of $\mathrm{ZnO}: \mathrm{Mo}(2 \%)$ is composed of two very broad overlapped bands (B1 ( 2.14 eV) and $\mathrm{B} 3(\sim 2.80 \mathrm{eV}))$ - covering the 1.4-3.4 eV energy region. Surprisingly, the $\mathrm{PL}$ spectrum of the $\mathrm{ZnO}: \mathrm{Mo}(5 \%)$ is single-band peaking at $2.64 \mathrm{eV}$ (B2 band with $1 \mathrm{eV}$ full width at half maximum (FWHM)). Furthermore, the B2 band is getting weaker upon the increased Mo content to 10 and $15 \%$ and the new clearly visible very narrow bands appear (B4-7 peaking at 2.96, 3.16, 3.24 and $3.34 \mathrm{eV}$, respectively). The B4-7 bands may be ascribed to exciton-like emission observed in $\mathrm{ZnO}$ [14], especially considering the existence of $\mathrm{ZnO}$ part in the complex zinc-molybdenum oxide creating $\mathrm{ZnO}: \mathrm{Mo}(10,15 \%)$ samples as discussed in the subsection above 
(see also Figure 1). The B4-7 bands are weaker in the $\mathrm{ZnO} \mathrm{Mo}(15 \%)$ sample. The new single-band spectra, B3' ( 2.91 eV), of the same amplitude are observed in the $\mathrm{ZnO}: \mathrm{Mo}(20,25 \%)$ samples. All of this confirms the gradual phase transformation upon the increased Mo content in the $\mathrm{ZnO}: \mathrm{Mo}(2-25 \%)$ samples.
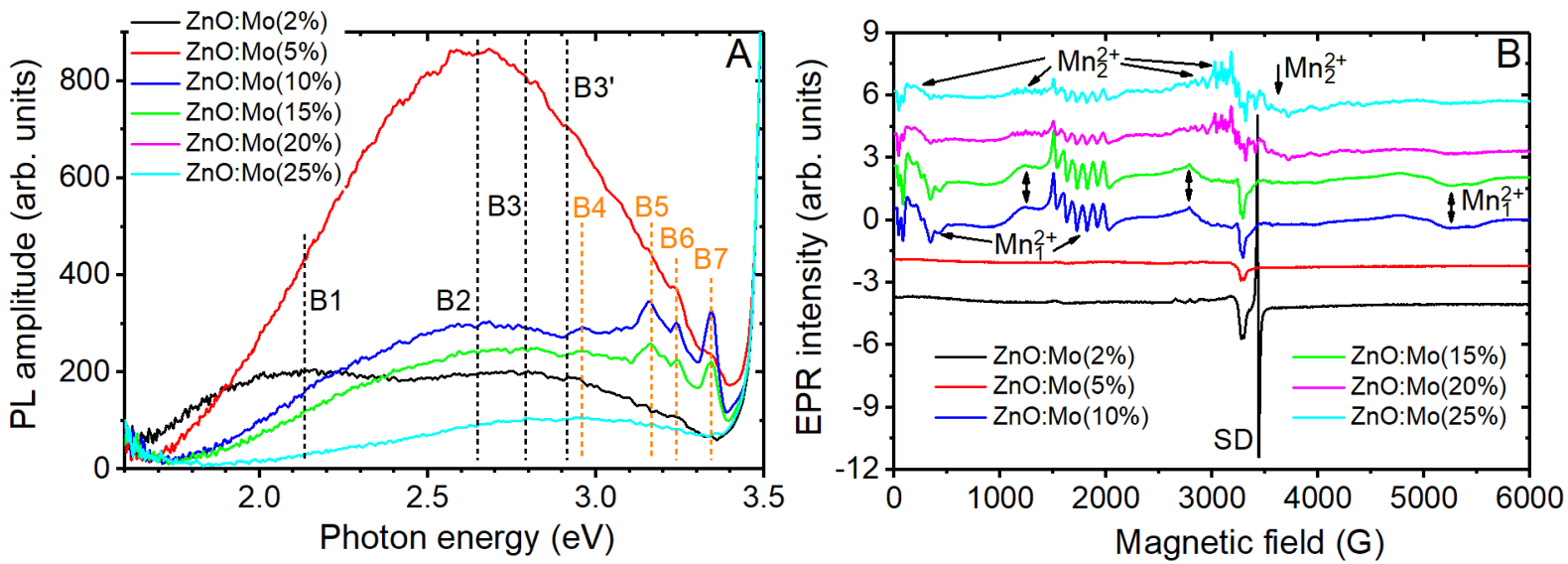

Figure 3 A - PL spectra measured in the ZnO:Mo(2-25\%). B1-3,3',4-7 indicate specific emission bands. The signal above $3.4 \mathrm{eV}$ is scattered light. B - EPR spectra measured in the $\mathrm{ZnO}: \mathrm{Mo}(2-25 \%)$. "SD" stands for

"shallow donors". $\mathrm{Mn}_{1,2}^{2+}$ and vertical double arrows indicate the spectra of two different $\mathrm{Mn}^{2+}$ centers.

In order to find out the presence of paramagnetic centers and their evolution upon the increased Mo content, EPR spectra were measured in all the $\mathrm{ZnO}: \mathrm{Mo}(2-25 \%)$ samples and shown in Figure 3B. Only the spectrum of the $\mathrm{ZnO}: \mathrm{Mo}(2 \%)$ was attributed with the SD signal at the $g$ factor $g=1.954$. The rest of visible signals were not identified. This signal is absent in the spectrum of the $\mathrm{ZnO}: \mathrm{Mo}(5 \%)$. Based on this fact and considering also the XRD results above, one may conclude that only the tiniest amount of $\mathrm{ZnO}$ phase exists in the $\mathrm{ZnO}: \mathrm{Mo}(5 \%)$ sample. The SD signal is absent in the EPR spectra of the $\mathrm{ZnO}: \mathrm{Mo}(10,15 \%)$. However, there are some resonances which were identified as belonging to $\mathrm{Mn}^{2+}$ (electron spin $S=5 / 2$ and the ${ }^{55} \mathrm{Mn}$ nucleus with $100 \%$ abundance and nuclear spin $I=5 / 2$ ), $\mathrm{Mn}_{1}^{2+}$ - there are five components due to $S=5 / 2$ with the one exhibiting the most pronounced hyperfine structure (sextet of lines because of $I=5 / 2$ with the center at 1738 G) [15]. The $\mathrm{Mn}_{1}^{2+}$ spectrum is getting weaker in the $\mathrm{ZnO}: \mathrm{Mo}(20,25 \%)$ samples, and the new $\mathrm{Mn}^{2+}$ spectrum appears $\left(\mathrm{Mn}_{2}^{2+}\right)$. It was identified using similar consideration as for the $\mathrm{Mn}_{1}^{2+}$ identification above. The $\mathrm{Mn}^{2+}$ is an accidental impurity but serves as a good indicator of the gradual material phase transformation. The SD signal is absent in the EPR spectra of the $\mathrm{ZnO}: \mathrm{Mo}(20,25 \%)$ as well. This correlates well to the XRD and PL measurements above.

\section{CONCLUSION}

It has been found that heavily Mo-doped hydrothermally grown $\mathrm{ZnO}$-based structures appear a mix of different zinc-molybdenum complex oxides upon the increased Mo content. Their morphology is changing upon the Mo doping level from microrods to microhexagons, then to micro- and nanoflakes and microslabs as well. This is confirmed by the observed transformations of PL and EPR spectra.

\section{ACKNOWLEDGEMENTS}

This work was supported by the Czech Science Foundation by the project No. 20-05497Y, CAS Mobility Plus project SAV-AV CR-21-09 and by the Scientific Grant Agency of Ministry of Education, Science, Research and Sport of Slovak Republic and Slovak Academy of Sciences (VEGA 2/0157/20). 


\section{REFERENCES}

[1] LEITER, F., ZHOU, H., HENECKER, F., HOFSTAETTER, A., HOFMANN, D. M., MEYER, B. K. Magnetic resonance experiments on the green emission in undoped ZnO crystals, Physica B. 2001, vol. 308-310, pp. 908911.

[2] LECOQ, P. Pushing the Limits in Time-of-Flight PET Imaging, IEEE Trans. Radiat. Plasma Med. Sci. 2017, vol. 1, pp. 473-485.

[3] NAJIB, S., BAKAN, F., ABDULLAYEVA, N., BAHARIQUSHCHI, R., KASAP, S., FRANZÒ, G., SANKIR, M., SANKIR, N. D., MIRABELLAD, S., ERDEM, E. Tailoring morphology to control defect structures in ZnO electrodes for high-performance supercapacitor devices, Nanoscale. 2020, vol. 12, pp. 16162-16172.

[4] TOUFANI, M., KASAP, S., TUFANI, A., BAKAN, F., WEBER, S., ERDEM, E. Synergy of nano-ZnO and 3Dgraphene foam electrodes for asymmetric supercapacitor devices, Nanoscale. 2020, vol. 12, pp. 12790-12800.

[5] FRODASON, Y. K., JOHANSEN, K. M., BJØRHEIM, T. S., SVENSSON, B. G., ALKAUSKAS, A. Zn vacancy as a polaronic hole trap in ZnO. Phys. Rev. B. 2017, vol. 95, 094105.

[6] BURYI, M., REMEŠ, Z., BABIN, V., ARTEMENKO, A., VANĚČEK, V., AUBRECHTOVÁ DRAGOUNOVÁ, K., LANDOVÁ, L., KUČERKOVÁ, R., MIČOVÁ, J. Transformation of free-standing ZnO nanorods upon Er doping, Applied Surface Science. 2021, vol. 562, 150217.

[7] BURYI, M., REMEŠ, Z., BABIN, V., VANĚČEK, V., AUBRECHTOVÁ DRAGOUNOVÁ, K., MIČOVÁ, J., LANDOVÁ, L., KUČERKOVÁ, R. ZnO nanorods alloyed with Mo/Er. The effect of postdeposition treatment on defect states and luminescence. IOP Conf. Ser.: Mater. Sci. Eng. 2021, vol. 1050, 012002.

[8] BURYI, M., REMEŠ, Z., BABIN, V., NOVOTNÝ, M., VANĚČEK, V., AUBRECHTOVÁ DRAGOUNOVÁ, K., MIČOVÁ, J., LANDOVÁ, L., KUČERKOVÁ, R., MORE-CHEVALIER, J., CHERTOPALOV, S., FITL, P., KMJEČ, $\mathrm{T}$. Influence of Mo doping on the luminescence properties and defect states in $\mathrm{ZnO}$ nanorods. Comparison with ZnO:Mo thin films, Applied Surface Science. 2021, vol. 555, 149679.

[9] JANOTTI, A., VAN DE WALLE, CH. G. Native point defects in ZnO. Phys. Rev. B. 2007, vol. 76, 165202.

[10] JANOTTI, A., VAN DE WALLE, CH. G. Fundamentals of zinc oxide as a semiconductor. Rep. Prog. Phys. 2009, vol. 72, 126501.

[11] GONZALES, C., BLOCK, D., COX, R. T., HERVÉ, A. Magnetic resonance studies of shallow donors in zinc oxide. J. Crystal Growth 1982, vol. 59, 357.

[12] BLOCK, D., HERVÉ, A., COX, R. T. Optically detected magnetic resonance and optically detected ENDOR of shallow indium donors in ZnQ. Phys. Rev. B 1982, vol. 25, 6049.

[13] MOONEY, J., KAMBHAMPATI, P. Get the Basics Right: Jacobian Conversion of Wavelength and Energy Scales for Quantitative Analysis of Emission Spectra. J. Phys. Chem. Lett. 2013, vol. 4, pp. 3316-3318.

[14] ÖZGÜR, Ü., ALIVOV, YA. I., LIU, C., TEKE, A., RESHCHIKOV, M. A., DOĞAN, S., AVRUTIN, V., CHO, S.-J., MORKOÇ, H. A comprehensive review of ZnO materials and devices. J. Appl. Phys. 2005, vol. 98, 041301.

[15] ABRAGAM, A., BLEANEY, B. Electron Paramagnetic Resonance of Transition lons. Oxford: Clarendon Press, 1970, vol. 1. 